\title{
Pulmonary Functions in Punjabi Type 2 Diabetics: Based on Chronicity of Disease
}

\author{
Navkaran Shergill and Ashok Kumar
}

\begin{abstract}
Aim: To observe pulmonary functions in two groups of Punjabi population, group 1 having type- 2 diabetes between 5 to 10 years and group 2 having type-2 diabetes for more than 10 years.Method: Fifty type- 2 diabetics (between 5 to 10 years) and fifty type-2 diabetics (more than 10 years) in the age range of 40-60 years participated in the study. The spirometery was performed to observe forced vital capacity (FVC), Forced Expiratory volume in 1 second (FEV1), (FEV1/FVC), peak expiratory flow rate (PEFR) and Forced expiration time (FET).Results: The mean age, height, weight and BMI of type-2 diabetics (between 5 to 10 years) and type-2 diabetics (more than 10 years) was $49.60 \pm 5.08$ years \& $52.58 \pm 4.69$ years, $172.16 \pm 5.72 \mathrm{~cm} \& 172.08 \pm 6.30 \mathrm{~cm}, 73.18 \pm 9.44 \mathrm{~kg} \& 70.36 \pm 9.16 \mathrm{~kg}$ and $24.72 \pm 3.33 \mathrm{~kg} / \mathrm{m}^{2} \& 23.74 \pm 2.68 \mathrm{~kg} / \mathrm{m}^{2}$. The mean FVC, FEV1, FEV1/FVC, PEF and FET of type-2 diabetics (between 5 to 10 years) and type-2 diabetics (more than 10 years) was

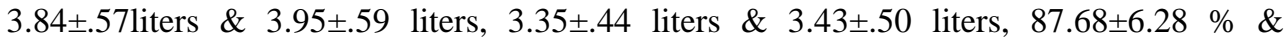
$87.12 \pm 5.12 \%, 8.52 \pm 1.14$ liters $/ \mathrm{sec} \& 8.73 \pm 1.22$ liters $/ \mathrm{sec}, 2.82 \pm .78 \mathrm{sec} \& 3.09 \pm .71 \mathrm{sec}$ respectively. Conclusion: It was concluded that with chroncitiy of type 2 diabetes, the various pulmonary function variables were reduced in Punjabi type- 2 diabetics. The reduced pulmonary functions in diabetics may be due to microangipathy of the alveolar capillary network in the lungs.
\end{abstract}

\author{
Navkaran Shergill \\ $\mathrm{Ph} . \mathrm{D}$. student \\ Department of Sports Science \\ Punjabi University Patiala (Punjab) India \\ E-mail:navkaran9999@gmail.com \\ Ashok Kumar \\ Associate Professor \\ Department of Sports Science \\ Punjabi University Patiala (Punjab) India
}

Key Words: : FVC, FEV1, PEF, FET, Spirometery

DOI: $10.18376 /$ jesp/2017/v13/i2/111279

\section{Introduction}

Type-2 diabetes mellitus is a metabolic disorder which is characterized by high blood glucose levels with insulin resistance and relative insulin deficiency (kumar et al, 2005). According to World Health Organization (WHO, 2008) both developed and developing nations are affected from this metabolic disease. About $6 \%$ of the total population of the world is affected by this monstrous disorder (Meetoo et al, 2007). A Catastrophic increase in the incidence of type 2 diabetes is being observed worldwide. It has been affecting life of people for thousands of years in different parts of the world and India is no exception. It is a multi-organ chronic disease and is associated with a ten year shorter life expectancy due to its complications (Williams). Pulmonary complications of the type 2-diabetes are ignored, despite the presence of large capillary network in the lungs. The alveolar capillary network in the lung is a large micro-vascular unit and may be affected by microangiopathy in type 2 diabetics (Sandler 1990). Neuropathy, retinopathy, nephropathy and cardiovascular dysfunctions as complications are common in diabetes mellitus. These 
complications are basically caused by micro-vascular damage which has a central role in the pathophysiology of type 2 diabetes (Bowden et al, 2010; Murea et al, 2012). Spirometry is widely used pulmonary function test (PFT). It is simple reliable, valid and powerful tool that assess, differentiate, follow-up and manage patients with pulmonary disorders. It typically assesses the lung volumes and flows, and is ideally suited to describe the effects of obstruction or restriction of lung function (Ruppel 1997). It noninvasively quantifies the physiological reserves in a large microvascular bed of lungs (Hsia, 2002). Now days, it is regarded as an integral component of any respiratory medical surveillance programme. PFT has assumed a key role in epidemiological studies investigating the incidence, natural history and causality of lung disease (McKay et al, 1984). Spirometry is essential for diagnosing respiratory illness, assessing their severity, determining response to treatment and tracking patient's progress over time (Jenkinsa 2009). Its utility was further recognized when its application was high lightened in diabetic patients (Meo et al, 2006). Pulmonary function in health are affected by ethnicity, gender, age, stature, environmental, genetic, socioeconomic, technical and other unidentified factors (Chhabra et al, 2015). The aetiology of diabetes in india is multifactorial and includes genetic factors coupled with environmental influences such as obesity associated with rising living standards, steady urban migration and lifestyle changes (Kaveeshwar and cornwall, 2014). With due course of time Type- 2 diabetes patients are at greater risk of developing respiratory infections or heart failures (Ehrlich et al 2010; Piccini et al 2004). The association between type-2 diabetes and impaired pulmonary function based on duration of the disease has not been frequently observed in Punjabi population. Therefore, the present study was conducted to observe pulmonary lung functions in Punjabi males having type- 2 diabetics between 5 to 10 years and more than 10 years.

Material and methods

The present study was conducted on 100 male subjects in the age range of 40 to 60years, out of which 50 subjects (Group 1) were having type-2 diabetes between 5 to 10 years and 50 subjects (Group 2) having type-2 diabetes for more than10 years, both diagnosed by physician. Details of the study were explained to each participant and signed consent was obtained from the participants. Subjects having type-2 diabetes for less than 5 years were excluded from the study. American diabetes association criteria was used to include subjects in the study, according to which a fasting glucose level of at least $7.0 \mathrm{mmol} / \mathrm{L}(126 \mathrm{mg} / \mathrm{dL})$; non fasting glucose level of at least $11.1 \mathrm{mmol} / \mathrm{L}$ $(200 \mathrm{mg} / \mathrm{dL})$; current use of anti-diabetic medications and a positive response to the question "has a doctor ever told you that you have diabetes (sugar in the blood)?" After taking the anthropometric data, the pulmonary function test was carried out as per the procedure recommended by American Thoracic Society (ATS) by using spirometer. Spirometer was ISO (9001:2000) certified spiroexcel of medicad company. The subjects were encouraged to practice the spirometry maneuver before doing the pulmonary function test. In addition, the next subject to be tested was asked to sit nearby and watch. The test was repeated three times at every 10 minute interval and the best out of three readings were taken into consideration. The result of two groups was compared with each other and the data was analyzed using the Statistical Package for Social Sciences (SPSS) version 20. All data was presented in mean, standard deviation, absolute and percent difference between two groups. Independent t-test was used to find the level of significant differences in the means of the outcome measures: age, height, weight, BMI, FVC, FEV1, FEV1/FVC, PEF and FET between the groups. The level of significance was $\mathrm{p}<0.05$.

\section{Results}

Table 1 shows that the mean age, height, weight and BMI of group 1 and group 2 was $49.60 \pm 5.08$ years \& 52.58 \pm 4.69 years, $172.16 \pm 5.72 \mathrm{~cm} \& 172.08 \pm 6.30 \mathrm{~cm}, 73.18 \pm 9.44 \mathrm{~kg} \&$ $70.36 \pm 9.16 \mathrm{~kg}$ and $24.72 \pm 3.33 \mathrm{~kg} / \mathrm{m}^{2} \& 23.74 \pm 2.68 \mathrm{~kg} / \mathrm{m}^{2}$ respectively. Further, it was found that the mean age of group 2 was more than group 1 (Table 1). In other words, an absolute and 
percentage difference of age of group 1 and group 2 was 2.98 years and $2.9 \%$ and this difference was statistical significant (Table 3). It was also found that the body weight of group 1 was more than group 2. An absolute and percent difference of weight of group 1 and group 2 was $2.82 \mathrm{~kg}$ and $1.9 \%$. Similarly the BMI of group 1 was more than group 2 and absolute and percent difference of BMI of group 1 and group 2 was $0.98 \mathrm{~kg} / \mathrm{m}^{2}$ and $2.02 \%$ and no statistical difference was found (Table 3).

\begin{tabular}{lcccc}
\multicolumn{4}{c}{ Table 1: Mean \pm SD of anthropometric variables of Group 1 and Group 2 } \\
\hline Variables & Group 1 & Group 2 & $\begin{array}{c}\text { Absolute } \\
\text { difference }\end{array}$ & $\begin{array}{c}\text { Percentage } \\
\text { difference }\end{array}$ \\
\hline Age (years) & $49.60 \pm 5.08$ & $52.58 \pm 4.69$ & 2.98 & $2.9 \%$ \\
Height $(\mathrm{cm})$ & $172.16 \pm 5.72$ & $172.08 \pm 6.30$ & 0.08 & $0.02 \%$ \\
Weight $(\mathrm{kg})$ & $73.18 \pm 9.44$ & $70.36 \pm 9.16$ & 2.82 & $1.9 \%$ \\
BMI & $24.72 \pm 3.33$ & $23.74 \pm 2.68$ & 0.98 & $2.02 \%$ \\
\hline
\end{tabular}

The mean Forced vital capacity (FVC), Forced expiratory volume in $1 \mathrm{sec}$ (FEV1), FVC/FEV1 (\%), Peak expiratory flow liters/sec (PEF) and Forced expiratory time (FET) of group 1 and group 2 was $3.84 \pm .57$ liters \& $3.95 \pm .59$ liters, $3.35 \pm .44$ liters \& $3.43 \pm .50$ liters, $87.68 \pm 6.28 \% \& 87.12 \pm 5.12 \%$, $8.52 \pm 1.14$ liters/sec \& $8.73 \pm 1.22$ liters/sec, $2.82 \pm .78 \mathrm{sec} \& 3.09 \pm .71 \mathrm{sec}$ respectively (table 2). Further it was found that the mean FVC of group 2 was slightly more than group 1 (Table 2) and the absolute difference and percentage difference was 0.11 liters and $1.41 \%$. But the mean of FEV1, PEF and FET was slightly more in group 2 than group 1 and absolute and percentage difference was $-0.08 \& 1.17 \%,-0.21 \& 1.21 \%,-0.27 \& 4.5 \%$ respectively. Again no statistical difference was found (Table 3).

\section{Discussion}

The result of the present study shows that the mean age of group 1 was $49.60 \pm 5.08$ year and group 2 was $52.58 \pm 4.69$ year. Further, it was found that the age of group 2 was more than group 1 i.e. the absolute and percent difference between two groups was 2.98 year \& $2.9 \%$ which was not statistically significant. In the present study, the subjects were randomly distributed in the two groups on the basis of age range of 40 to 60 years and not on age matching criteria and this may be the reason that there was a statistical significant difference in their age. The weight of group 1 $(73.18 \pm 9.4 \mathrm{~kg})$ was more than group $2(70.36 \pm 9.1 \mathrm{~kg})$ and this difference was again not statistically significant. The BMI of group $1\left(24.72 \pm 3.33 \mathrm{~kg} / \mathrm{m}^{2}\right)$ was more than group $2\left(23.74 \pm 2.68 \mathrm{~kg} / \mathrm{m}^{2}\right)$ and this difference was not statistically significant. In type 2 diabetics, the insufficient insulin prevents the body from getting glucose from the blood into the body cells to use as energy. When this occurs, the body starts burning fat and muscle (protein) for energy, causing a reduction in overall body weight. According to WHO (2006) BMI ranges are underweight: under $18.5 \mathrm{~kg} / \mathrm{m}^{2}$, normal weight: 18.5 to $25 \mathrm{~kg} / \mathrm{m}^{2}$, overweight: 25 to $30 \mathrm{~kg} / \mathrm{m}^{2}$ and obese: over $30 \mathrm{~kg} / \mathrm{m}^{2}$. In the present study, the BMI of both groups i.e group 1 and group 2, was found to be in normal weight range 
Journal of Exercise Science \& Physiotherapy, Vol. 13, No. 2, 2017

ISSN: 0973-2020 (Print) $\quad \mathrm{I}_{2}$ OR Impact Factor = 5.23 UGC Approved [Journal No.7485] ISSN: 2454-6089 (online)

Table 2: Mean \pm SD of Pulmonary function variables of Group 1 and Group 2

\begin{tabular}{llll}
\hline Variables & Group 1 & Group 2 & Absolute differencePercentage difference
\end{tabular}

\begin{tabular}{lcccc}
\hline FVC (L) & $\mathbf{3 . 8 4} \pm .57$ & $3.95 \pm .59$ & $-\mathbf{0 . 1 1}$ & $1.41 \%$ \\
FEV1(L) & $\mathbf{3 . 3 5} \pm .44$ & $3.43 \pm .50$ & $-\mathbf{0 . 0 8}$ & $1.17 \%$ \\
FEV1/FVC & $\mathbf{8 7 . 6 8} \pm 6.28$ & $\mathbf{8 7 . 1 2} \pm 5.12$ & $\mathbf{0 . 5 6}$ & $\mathbf{0 . 3 2 \%}$ \\
PEF (L/S) & $\mathbf{8 . 5 2} \pm \mathbf{1 . 1 4}$ & $\mathbf{8 . 7 3} \pm \mathbf{1 . 2 2}$ & $\mathbf{- 0 . 2 1}$ & $1.21 \%$ \\
FET100\% (S) & $\mathbf{2 . 8 2} \pm .78$ & $\mathbf{3 . 0 9} \pm .71$ & -0.27 & $4.5 \%$ \\
\hline
\end{tabular}

FVC- Forced vital capacity; FEV1-Forced expiratory volume in 1 sec; FEV1/FVC- Ratio of

Forced expiratory volume in 1 sec by Forced vital capacity; PEF- Peak expiratory volume; FET- forced expiration time

Table 3. Independent t-test of anthropometric variables and pulmonary function variables

\begin{tabular}{lccc}
\hline Variables & $t$ & Sig. (2-tailed) & $\begin{array}{c}\text { Mean } \\
\text { Difference }\end{array}$ \\
\hline Age & & & -2.98 \\
Height & -3.044 & .003 & .08 \\
Weight & .066 & .947 & 2.82 \\
BMI & 1.515 & .133 & .97 \\
FVC (L) & 1.617 & .109 & -.10 \\
FEV1 (L) & -.912 & .364 & -.07 \\
FEV1/FVC\% & -.839 & .403 & .55 \\
PEF (L/S) & .483 & .630 & -.20 \\
FET 100\%(S) & -.860 & .392 & -.26 \\
\hline
\end{tabular}

BMI- Body mass index; FVC- Forced vital capacity; FEV1-Forced expiratory volume in 1 sec; FEV1/FVC- Ratio of Forced expiratory volume in 1 sec by Forced vital capacity; PEF- Peak expiratory volume; FET- forced expiration time

The results of the present study shows that the mean FVC in Group 1 was 3.84 \pm .57 liters and group 2 was $3.95 \pm .59$ liters. It was found that FVC of group 2 was more than group 1 and the absolute and percent difference was 0.11 liters and $1.4 \%$ which was not statistically significant. The FEV 1 in Group 1 was $3.35 \pm .44$ liters and group 2 was $3.43 \pm .50$ liters, again it was found that FEV 1 was more in group 2. Further the absolute and percent difference between both groups was 0.08 liters and $1.2 \%$, which was not statistically significant. The results of the present study also showed that PEF in group 1 was $8.52 \pm 1.14$ liters per second and group 2 was $8.73 \pm 1.22$ liters per second, further it was found that PEF was more in group 2 than group 1, which was again not statistically significant. The FEV1/FVC in group 1 was $87.68 \pm 6.28 \%$ and in group 2 was $87.12 \pm 5.12 \%$ further it was found that FEV1/FVC was slightly more in group 1 than group 2 . The percent difference between both groups was $.32 \%$, it was not statistically significant. The FET in group 1 was

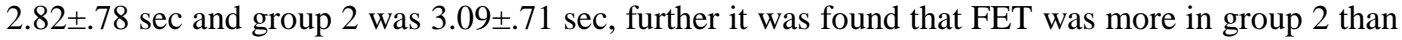
group 1. Absolute and percentage difference was $0.27 \mathrm{sec}$ and $4.5 \%$. According to a study by Chhabra et al (2014) predicted values for Pulmonary lung function variables like FVC, FEV1,

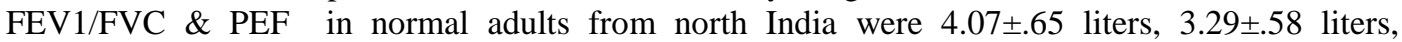


$80.3 \pm 6.09 \%$ and $8.01 \pm 1.5$ liters per second. The FVC of Punjabi type- 2 diabetics of both groups in present study was observed to be reduced as compared to these values. Chronic hyperglycemia associated with the diabetic state leads to glycosylation of serum and tissue proteins and the formation of advanced glycosylation end products. Following their deposition within tissues, the glycosylated proteins pro-inflammatory effects, that may result in pulmonary inflammation and which further causes airway damage (Nandhini 2010). There is over-production of mitochondrial superoxide's and ultimately a reduction in antioxidant defense resulting in increased oxidative activity associated with diabetes and hence, increased susceptibility to environmental oxidative insults, which leads to subsequent loss of lung function (Ali, 2010 ; Agarwal, 2010).

\section{Conclusion}

It was concluded that with chroncitiy of type 2 diabetes, the various pulmonary function variables were reduced in Punjabi type- 2 diabetics. The reduced pulmonary functions in diabetics may be due to microangipathy of the alveolar capillary network in the lungs.

\section{Acknowledgement}

The authors thank all subjects who voluntarily participated in the study.

\section{References}

Anjana RM, Ali MK, Pradeepa R, Deepa M, Datta M, Unnikrishnan R, Rema M, Mohan V (2011). The need for obtaining accurate nationwide estimates of diabetes prevalence in India - rationale for a national study on diabetes. Indian J Med Res;133:369-8.

Kumar V, Fautso N, Abbas AK, Corton RS, Robbins SL (2005). Robbins and Cotran Pathologic Basis of disease ( $7^{\text {th }}$ ed). Philadelphia, Saunders: pp 1194-1195. ISBN 0-7216-0187-1.

Williams textbook of endocrinology. (12 ${ }^{\text {th }}$ ed.) Philadelphia: Elsevier/Saunders.pp. 1371-1435. ISBN 978-14377-0324-5.

Kaveeshwar SA and Cornwall J (2014). The current status of diabetes mellitus in India. Aust Med J. 7(1): 4548.

Ehrlich SF, Quesenberry CP, Eden SK, Shah J, Ferrara A (2010). Patients diagnosed with diabetes are at increased risk for asthma, COPD, pulmonary fibrosis and pneumonia but not lung cancer. Diabetes care; 33:55-60.

Piccini JP, Klein L, Gheorghiade M, Bonow RO (2004). New insight into diastolic heart failure: role of diabetes mellitus. Am J Med ; 116:645-755.

Chhabra SK, Kumar R, Gupta U, Rahman M, Dash DJ (2014) Prediction equations for spirometery in adults from north india. Indian J Chest Allied sci 2014;56:221-229.

Bowden DW, Cox AJ, Freedman BI, Hugenschimdt CE, Wagenknecht LE, Herrington D, Agarwal S, Register TC, Maldjiam JA (2010). Review of Diabetes Heart Study (DHS) family of studies of comprehensively examined sample for genetic and epidemiological studies for type 2 diabetes and its complications. Rev Diabet Stud. 7(3): 188-201.

Murea M, Ma L, Freedman BL (2012). Genetic and environmental factors associated with type 2 diabetes and diabetic vascular complications. Rev Diabet Stud. 9(1): 6-22.

Hsia CC (2002). Recruitment of lung diffusing capacity: update of concept and application. Chest 2002; 122:1774-83.

Meo SA, Al Dress AM, Arif M, Al-Rubean K. (2006). Lung functions in type 2 Saudi diabetic patients. Saudi Med J. 27(3): 338-343.

Jenkinsa C. (2009). Spirometry performance in primary care: the problem and possible solutions. Primary care Respir J. 18(3): 128-139.

McKay, Ray T, Horvath E .(1984). Pulmonary function testing in industry In: Carl Zenz O, Dickerson Bruca, Horvath Edward P, editors Occupational medicine. London: mosby. p. 229.

Ruppel GL (1997). Pulmonary function testing, Trends and techniques. Resp Care Clinics North America. 3:155-81.

Conflict of Interest: None Declared 